\title{
Conversion to aflibercept for diabetic macular edema unresponsive to ranibizumab or bevacizumab
}

This article was published in the following Dove Press journal:

Clinical Ophthalmology

16 September 2015

Number of times this article has been viewed

\author{
Laurence S Lim ${ }^{1,2}$ \\ Wei Yan $\mathrm{Ng}^{2}$ \\ Ranjana Mathur ${ }^{2}$ \\ Doric Wong ${ }^{2}$ \\ Edmund YM Wong ${ }^{2}$ \\ Ian $\mathrm{Yeo}^{2}$ \\ Chui Ming Gemmy Cheung ${ }^{2}$ \\ Shu Yen Lee ${ }^{2}$ \\ Tien Yin Wong ${ }^{2}$ \\ Thanos D Papakostas' \\ Leo A Kim' \\ 'Retina Service, Massachusetts \\ Eye and Ear Infirmary, Harvard \\ Medical School, Boston, MA, USA; \\ ${ }^{2} V$ itreoretinal Department, Singapore \\ National Eye Centre, Singapore
}

Correspondence: Laurence Lim

Vitreoretinal Department,

Singapore National Eye Centre,

II Third Hospital Avenue,

Singapore 16875 I

Tel +65 63228335

Email Ilimshen@gmail.com
Background: The purpose of this study was to determine if eyes with diabetic macular edema (DME) unresponsive to ranibizumab or bevacizumab would benefit from conversion to aflibercept.

Methods: This study was conducted as a retrospective chart review of subjects with DME unresponsive to ranibizumab and/or bevacizumab and subsequently converted to aflibercept.

Results: In total, 21 eyes from 19 subjects of mean age $62 \pm 15$ years were included. The majority of subjects were male (63\%). The median number of ranibizumab or bevacizumab injections before switching to aflibercept was six, and the median number of aflibercept injections after switching was three. Median follow-up was 5 months after the switch. Mean central foveal thickness (CFT) was $453.52 \pm 143.39 \mathrm{~mm}$ immediately prior to the switch. Morphologically, intraretinal cysts were present in all cases. Mean CFT after the first injection decreased significantly to $362.57 \pm 92.82 \mathrm{~mm}$ (Wilcoxon signed-rank test; $P<0.001$ ). At the end of follow-up, the mean CFT was $324.17 \pm 98.76 \mathrm{~mm}(P<0.001)$. Mean visual acuity was $0.42 \pm 0.23 \log$ MAR just prior to the switch, $0.39 \pm 0.31 \log \mathrm{MAR}$ after one aflibercept injection, and $0.37 \pm 0.22 \log$ MAR at the end of follow-up. The final visual acuity was significantly better than visual acuity before the switch $(P=0.04)$.

Conclusion: Eyes with DME unresponsive to multiple ranibizumab/bevacizumab injections demonstrate anatomical and visual improvement on conversion to aflibercept.

Keywords: diabetic retinopathy, macular edema, aflibercept, bevacizumab, ranibizumab

\section{Introduction}

Diabetic retinopathy is a major cause of visual loss worldwide, with vision-threatening diabetic retinopathy being present in $10 \%$ of people with diabetes. Diabetic macular edema (DME) is the main cause of visual impairment in diabetic retinopathy, and there is ample evidence for the role of vascular endothelial growth factor (VEGF) in the pathogenesis of DME. ${ }^{1-6}$ Several large clinical trials have established the important role of the anti-VEGF agents, ranibizumab and bevacizumab, in the treatment of DME. ${ }^{7-12}$

Aflibercept is a novel anti-VEGF agent composed of the VEGF-binding portions of the extracellular domains of human VEGF receptors 1 and 2 fused to the Fc portion of human immunoglobulin G1. Aflibercept functions as a soluble decoy receptor. The DA VINCI, VISTA, and VIVID studies have established that treatment with aflibercept yields greater visual gains than macular laser treatment, and the drug has since received US Food and Drug Administration approval for this indication. ${ }^{13-15}$ A recent trial has also demonstrated that aflibercept is superior to ranibizumab or bevacizumab for eyes with DME and poorer presenting acuity. 
Currently, many patients who have received ranibizumab or bevacizumab for the treatment of DME and who have failed to respond to these drugs are being switched to aflibercept. Differences in the pharmacodynamics of aflibercept compared with ranibizumab or bevacizumab have been the basis of this strategy. Unlike ranibizumab, aflibercept binds VEGF with much greater affinity and also binds placental growth factor. Some patients may also be switched to aflibercept due to its reportedly longer duration of action. There are currently few data on the outcomes following this therapeutic switch. Retrospective data from subjects receiving this treatment for age-related macular degeneration have suggested that anatomical improvement with less significant visual improvement can be expected.

The aim of this study was to evaluate the short-term outcomes following conversion from ranibizumab or bevacizumab therapy to aflibercept for the treatment of refractory DME.

\section{Materials and methods}

This was a retrospective series of patients treated at two tertiary eye care centers, ie, Singapore National Eye Centre and Massachusetts Eye and Ear Infirmary. Subjects were identified from electronic medical records using the appropriate International Classification of Diseases and billing codes. Subjects were included if they had been treated for DME with ranibizumab and/or bevacizumab and were subsequently converted to aflibercept between September 2012 and September 2014. Exclusion criteria included other visually significant ocular pathology and complications of diabetic retinopathy (eg, tractional retinal detachment, vitreous hemorrhage), loss to follow-up, fewer than three ranibizumab and/or bevacizumab injections prior to conversion to aflibercept, and incomplete imaging or clinical data.

Patient demographics, systemic comorbidities, and patients' diabetes control ( $\mathrm{HbA}_{1 \mathrm{c}}$ levels) were recorded. The main outcomes of note were the best-corrected visual acuity, which was recorded as Snellen visual acuity and converted to $\log$ MAR equivalents for analysis, and the anatomical changes as documented on optical coherence tomography. Spectral-domain optical coherence tomography was performed using the Cirrus (Carl Zeiss Meditec, Dublin, CA, USA) or Spectralis (Heidelberg Engineering, Heidelberg, Germany) platforms. The main optical coherence tomography measures of note were central foveal thickness (CFT) as well as the presence of intraretinal or subretinal fluid on the tomogram. The CFT values were automatically generated by the imaging software and used in the analyses after the tomograms had been reviewed for segmentation errors. In cases where segmentation errors were seen, the CFT was manually measured from the tomogram showing the greatest foveal elevation. Intraretinal or subretinal fluid was classified dichotomously as either present or absent, with cases in which only trace fluid was seen (very fine intraretinal cysts or very thin slivers of subretinal fluid) being classified as absent.

The study complied with the Health Insurance Portability and Accountability Act of 1996 and was performed in accordance with the tenets of the Declaration of Helsinki as revised in 1989. This was an observational, retrospective, noninterventional study, and approval and waiver of consent were obtained from the institutional review boards of both institutions.

\section{Results}

In total, 21 eyes were included from 19 subjects. Their mean age was $62 \pm 15$ years and most were male $(63 \%)$. The mean $\mathrm{HbA}_{1 \mathrm{c}}$ was $6.9 \% \pm 0.7 \%$. Of the 21 eyes, nine had received panretinal photocoagulation. Fifteen eyes had received focal laser before the switch and none after. The median number of ranibizumab or bevacizumab injections before switching to aflibercept was six, and the median number of aflibercept injections after switching was three. Median follow-up was 5 months after the switch.

The mean interval between bevacizumab/ranibizumab injections prior to the switch was $2.4 \pm 2.2$ months and the interval between aflibercept injections was $2.4 \pm 2.2$ months $(P=0.92)$. The mean CFT at presentation was $385.65 \pm 115.16$ and $431.18 \pm 147.79 \mu \mathrm{m}$ immediately prior to the switch $(P=0.17)$. Morphologically, intraretinal cysts were present in all cases. The mean CFT after the first aflibercept injection reduced significantly to $362.57 \pm 92.82 \mathrm{~mm}$ (Wilcoxon signed-rank test; $P<0.001)$. At the end of follow-up, the mean CFT was $324.17 \pm 98.76 \mathrm{~mm}(P<0.001$, Figure 1$)$. The mean visual acuity was $0.42 \pm 0.23 \log$ MAR just prior to the switch, $0.39 \pm 0.31 \operatorname{logMAR}$ after one aflibercept injection, and $0.37 \pm 0.22 \operatorname{logMAR}$ at the end of follow-up (Figure 2). The final visual acuity was significantly better compared with the visual acuity before the switch $(P=0.04)$. Three of the 21 eyes $(14 \%)$ had complete resolution of intraretinal cysts at the end of follow-up.

A representative case is shown in Figure 3. A 78-year-old woman had long-standing diabetes with a recent $\mathrm{HbA}_{1 \mathrm{c}}$ of $7.5 \%$. After four bevacizumab injections, the right eye had persistent center-involving DME with a CFT of $516 \mathrm{~mm}$ and large cystoid spaces (Figure 3A). The CFT reduced to $455 \mathrm{~mm}$ after one aflibercept injection (Figure 3B). After six aflibercept injections, the CFT was $357 \mathrm{~mm}$ and the cystoid spaces had resolved, although a hyperreflective clump of hard exudates was still seen with disruption of the ellipsoid zone (Figure 3C). 


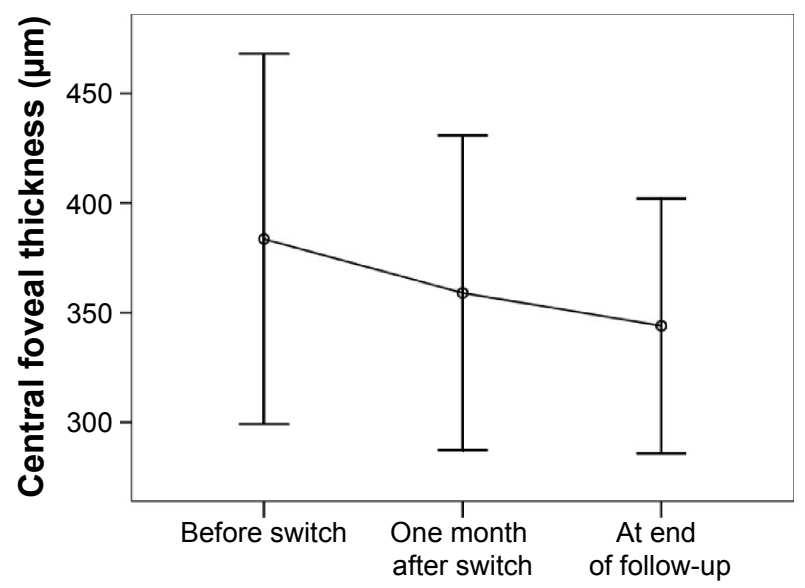

Figure I Change in mean central foveal thickness $(\mu \mathrm{m})$.

\section{Discussion}

In the course of DME treatment, physicians may choose to switch between anti-VEGF agents for various reasons. Clinical reasons include the theoretically greater affinity of aflibercept for VEGF as well as the fact that it also binds to and neutralizes placental growth factor. These pharmacodynamic differences may be particularly useful in situations unresponsive to ranibizumab or bevacizumab. In addition, physicians may choose to switch a patient to aflibercept to take advantage of its reportedly longer duration of action.

Anti-VEGF treatment with bevacizumab or ranibizumab has been clearly shown to be effective and superior to laser for the treatment of DME involving the foveal center. Pegaptanib was the first anti-VEGF agent shown to be effective in the management of DME. ${ }^{16}$ Several large trials, including the READ-2 study, ${ }^{7}$ RESOLVE, ${ }^{8}$ and the Diabetic Retinopathy Clinical Research (DRCR) Network group studies, ${ }^{9,10}$ have shown anti-VEGF treatment with bevacizumab or ranibizumab to be superior to laser alone. Despite these encouraging results with anti-VEGF agents, some cases either do not respond at all to ranibizumab or bevacizumab, or demonstrate an initial response to treatment followed by subsequent nonresponse to further treatment or during disease reactivation. Various mechanisms

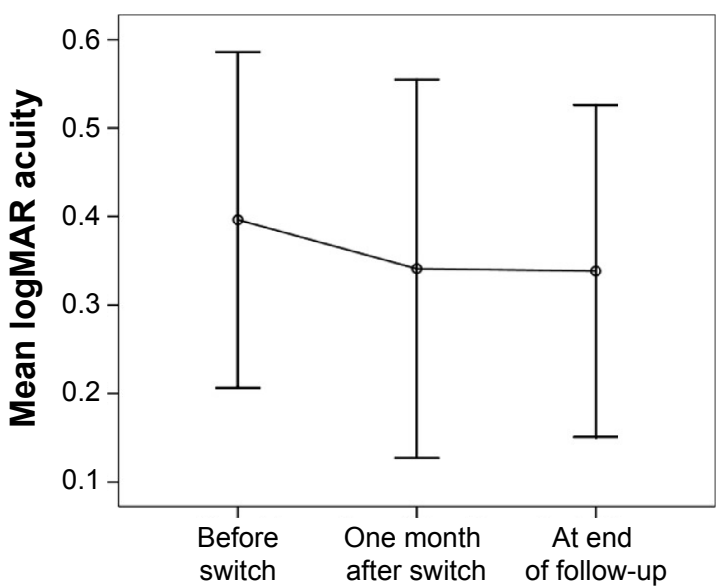

Figure 2 Change in mean logMAR visual acuity.

may underlie this loss of therapeutic effect. Pharmacodynamic mechanisms include increased VEGF expression from inflammatory cells and upregulation of VEGF receptors, while pharmacokinetic tolerance represents an immune response to the anti-VEGF antibodies injected leading to rapid clearance. In these cases, other agents may be used to suppress VEGF. For example, an intravitreal dexamethasone implant $\left(\mathrm{Ozurdex}^{\circledR}\right)$ has been shown to be effective in eyes unresponsive to treatment with bevacizumab or ranibizumab. ${ }^{17}$

More recently, aflibercept has likewise been shown to be effective in the treatment of center-involving DME, producing results comparable with those for ranibizumab and bevacizumab. The DA VINCI trial evaluated different doses and dosing regimens of aflibercept with laser photocoagulation in eyes with DME. ${ }^{13,14}$ Patients with center-involving DME were assigned to either laser treatment or one of four aflibercept dosing groups. At 24 weeks, all the aflibercept groups had greater visual gains than the laser group, with mean improvements in acuity ranging from 8.5 to 11.4 letters for the aflibercept groups compared with 2.5 letters for the laser group. The differences were even more distinct at 52 weeks, with letter mean gains of 9.7-12.0 in the aflibercept groups versus a mean letter loss of 1.3 in the laser group.
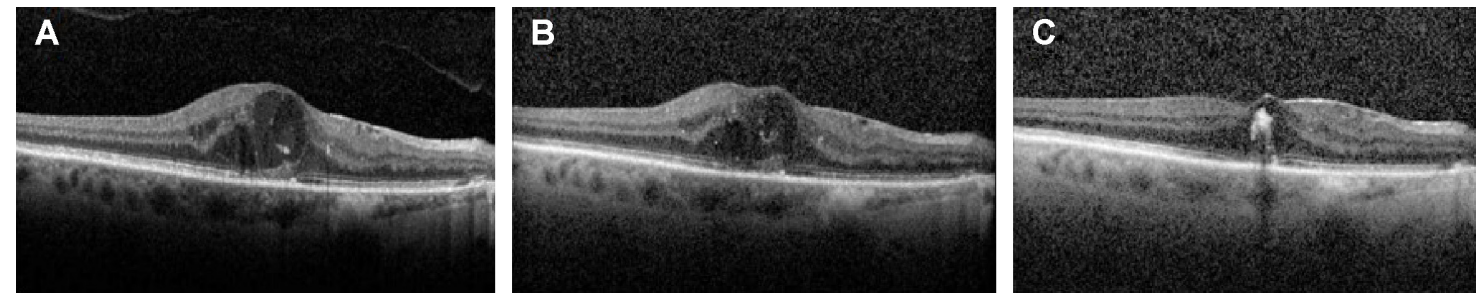

Figure 3 This 78-year-old woman had long-standing diabetes with a recent $\mathrm{HbA}_{\mathrm{lc}}$ of $7.5 \%$.

Notes: (A) After four bevacizumab injections, the right eye had persistent center-involving diabetic macular edema with a CFT of $5 \mathrm{I} 6 \mathrm{~mm}$ and large cystoid spaces. (B) The CFT decreased to $455 \mathrm{~mm}$ after one aflibercept injection. (C) After six aflibercept injections, the CFT was $357 \mathrm{~mm}$ and the cystoid spaces had resolved, although a hyperreflective clump of hard exudates was still seen with ellipsoid zone disruption.

Abbreviations: CFT, central foveal thickness; $\mathrm{HbA}_{\mathrm{lc}}$, glycated hemoglobin. 
All the aflibercept groups also demonstrated significantly greater reductions in CFT compared with the laser group. The VISTA and VIVID trials have shown similar results, with aflibercept being superior to laser. ${ }^{18}$ The DRCR Network has recently published the results of a seminal trial comparing the three anti-VEGF agents for DME. ${ }^{19}$ Over 1 year, eyes with presenting visual acuity worse than approximately 20/50 experienced greater visual improvement on treatment with aflibercept compared with bevacizumab or ranibizumab, with mean letter gains of 18.9 with aflibercept, 11.8 with bevacizumab, and 14.2 with ranibizumab. These studies suggest that cases unresponsive to ranibizumab and bevacizumab may respond instead to aflibercept.

To our knowledge, there are limited data on the results of switching to aflibercept after treatment with ranibizumab or bevacizumab for DME. Our study is limited by its small sample size and the inherent limitations of a retrospective report. Different optical coherence tomography platforms were also used, although each patient was always imaged with the same platform for follow-up scans. Nevertheless, significant visual and anatomical improvement with CFT reduction were seen after just one injection and at the end of follow-up. Our findings are consistent with those of the DRCR Network study, ${ }^{19}$ and support the notion that aflibercept may be more effective than ranibizumab or bevacizumab for more resistant cases. However, complete elimination of chronic cystoid spaces is difficult, and longer follow-up is needed to determine the effects of these lesions on vision.

\section{Conclusion}

Patients with center-involving DME who are unresponsive to ranibizumab or bevacizumab demonstrate anatomical and visual improvements after conversion to aflibercept. While aflibercept injections are much more costly than bevacizumab, the improvement that can be anticipated in these challenging cases suggests that making the switch is justifiable. Further study is warranted to determine if injection intervals can be extended with aflibercept.

\section{Disclosure}

The authors report no conflicts of interest in this work.

\section{References}

1. Scholl S, Kirchhof J, Augustin AJ. Pathophysiology of macular edema. Ophthalmologica. 2010;224 Suppl 1:8-15.

2. Rajappa M, Saxena P, Kaur J. Ocular angiogenesis: mechanisms and recent advances in therapy. Adv Clin Chem. 2010;50:103-121.

3. Cheung N, Mitchell P, Wong TY. Diabetic retinopathy. Lancet. 2010; 376:124-136.

4. Zhang X, Bao S, Hambly BD, Gillies MC. Vascular endothelial growth factor-A: a multifunctional molecular player in diabetic retinopathy. Int J Biochem Cell Biol. 2009;41:2368-2371.

5. Jardeleza MS, Miller JW. Review of anti-VEGF therapy in proliferative diabetic retinopathy. Semin Ophthalmol. 2009;24:87-92.

6. Tolentino MJ. Current molecular understanding and future treatment strategies for pathologic ocular neovascularization. Curr Mol Med.2009; 9:973-981.

7. Nguyen QD, Shah SM, Heier JS, Do DV, Lim J, Boyer D. Primary end point (six months) results of ranibizumab for edema of the macula in diabetes (READ-2) study. Ophthalmology. 2009;116:2175-2181.

8. Massin P, Bandello F, Garweg JG, et al. Safety and efficacy of ranibizumab in diabetic macular edema (RESOLVE Study): a 12-month, randomized, controlled, double-masked, multicenter phase II study. Diabetes Care. 2010;33:2399-2405.

9. Elman MJ, Aiello LP, Beck RW, et al. Randomized trial evaluating ranibizumab plus prompt or deferred laser or triamcinolone plus prompt laser for diabetic macular edema. Ophthalmology. 2010;117:1064-1077.

10. Elman MJ, Bressler NM, Qin H, et al. Expanded 2-year follow-up of ranibizumab plus prompt or deferred laser or triamcinolone plus prompt laser for diabetic macular edema. Ophthalmology. 2011;118:609-614.

11. Mitchell P, Bandello F, Schmidt-Erfurth U, et al. The RESTORE study: ranibizumab monotherapy or combined with laser versus laser monotherapy for diabetic macular edema. Ophthalmology. 2011;118:615-625.

12. Arevalo JF, Fromow-Guerra J, Quiroz-Mercado H, et al. Primary intravitreal bevacizumab (Avastin) for diabetic macular edema: results from the Pan-American Collaborative Retina Study Group at 6-month follow-up. Ophthalmology. 2007;114:743-750.

13. Do DV, Nguyen QD, Boyer D, et al. One-year outcomes of the DA VINCI study of VEGF trap-eye in eyes with diabetic macular edema. Ophthalmology. 2012;119:1658-1665.

14. Do DV, Schmidt-Erfurth U, Gonzalez VH, et al. The DA VINCI Study: phase 2 primary results of VEGF Trap-Eye in patients with diabetic macular edema. Ophthalmology. 2011;118:1819-1826.

15. Do DV, Nguyen QD, Shah SM, et al. An exploratory study of the safety, tolerability and bioactivity of a single intravitreal injection of vascular endothelial growth factor Trap-Eye in patients with diabetic macular oedema. Br J Ophthalmol. 2009;93:144-149.

16. Pacella E, La Torre G, Impallara D, et al. Efficacy and safety of the intravitreal treatment of diabetic macular edema with pegaptanib: a 12-month follow-up. Clin Ter. 2013;164:e121.

17. Pacella E, Vestri AR, Muscella R, et al. Preliminary results of an intravitreal dexamethasone implant $\left(\right.$ Ozurdex $\left.^{\circledR}\right)$ in patients with persistent diabetic macular edema. Clin Ophthalmol. 2013;7:1423-1428.

18. Korobelnik JF, Do DV, Schmidt-Erfurth U, et al. Intravitreal aflibercept for diabetic macular edema. Ophthalmology. 2015;15:52.

19. Wells JA, Glassman AR, Ayala AR, et al. Aflibercept, bevacizumab, or ranibizumab for diabetic macular edema. N Engl J Med. 2015;372: 1193-1203.

\section{Dovepress}

\section{Publish your work in this journal}

Clinical Ophthalmology is an international, peer-reviewed journal covering all subspecialties within ophthalmology. Key topics include: Optometry; Visual science; Pharmacology and drug therapy in eye diseases; Basic Sciences; Primary and Secondary eye care; Patient Safety and Quality of Care Improvements. This journal is indexed on Submit your manuscript here: http://www.dovepress.com/clinical-ophthalmology-journal
PubMed Central and CAS, and is the official journal of The Society of Clinical Ophthalmology (SCO). The manuscript management system is completely online and includes a very quick and fair peer-review system, which is all easy to use. Visit http://www.dovepress.com/ testimonials.php to read real quotes from published authors. 